\title{
BMJ Open Disturbing medical findings in war- related traumatic amputation patients: a clinical descriptive study from Gaza
}

\author{
Hanne Edoy Heszlein-Lossius (10 , ${ }^{1}$ Anas Ismail,, ${ }^{2,3}$ Yahya Al-Borno, ${ }^{3}$ \\ Samar Shaqqoura, ${ }^{3}$ Nashwa Skaik, ${ }^{3}$ Iman Al Hinnawi, ${ }^{3}$ Mahmoud Matar, ${ }^{3}$ \\ Mads Gilbert ${ }^{1,4}$
}

To cite: Heszlein-Lossius HE, Ismail A, Al-Borno Y, et al. Disturbing medical findings in war-related traumatic amputation patients: a clinical descriptive study from Gaza. BMJ Open 2020;10:e034648. doi:10.1136/ bmjopen-2019-034648

- Prepublication history for this paper is available online. To view these files, please visit the journal online (http://dx.doi. org/10.1136/bmjopen-2019034648).

Received 04 October 2019 Revised 25 February 2020 Accepted 22 May 2020

Check for updates

(c) Author(s) (or their employer(s)) 2020. Re-use permitted under CC BY-NC. No commercial re-use. See rights and permissions. Published by BMJ.

${ }^{1}$ The Anaesthesia and Critical Care Research Group, Institute of Clinical Medicine, The Arctic University of Norway, Tromsø, Norway

${ }^{2}$ Faculty of Medicine, Al-Azhar University, Gaza, Palestine

${ }^{3}$ Al-Shifa Medical Centre, Gaza, Palestine

${ }^{4}$ Clinic of Emergency Medicine, University Hospital of North Norway, Tromsø, Norway

Correspondence to Dr Hanne Edoy Heszlein-

Lossius;

hannelossius@gmail.com

\section{ABSTRACT}

Objectives The aim of this study was to explore possible long-term negative health effects of injuries sustained by modern weaponry.

Setting The study was conducted in Gaza's main hospital, Al-Shifa Hospital.

Participants During the last 10 to 15 years, thousands of civilian Palestinians in Gaza have survived numerous military incursions, but with war-related traumatic injuries caused by explosive weapons. It is unclear to which extent the injuries sustained by such modern weaponry may increase survivors' risks of negative long-term health effects and serious illness. We have reported mechanisms and severity of injury, demographics and psychosocial status among 254 Palestinian patients in Gaza with war-related extremity amputations. Among the same amputees, subgroups of patients presented a variety of alarming symptoms and findings. 94 patients received further diagnostic clinical exploration, radiology imaging and clinical chemistry laboratory tests at the main clinical centre in Gaza, the Al-Shifa Hospital.

Results Nine out of ten of the referred patients were young (median 31.5 years) males (88/94, 92.6\%). Ultrasound imaging revealed that 19 of 90 patients $(20 \%)$ had fatty liver infiltration, 3 patients had lung nodules and 10 patients had lung atelectasis on chest CT. Twelve had remaining shrapnel(s) in the chest, five patients had shrapnel(s) in the abdomen and one in the scrotum. We found shrapnel(s) in the amputation stumps of 26 patient's amputated limbs, while 8 patients had shrapnel in the non-amputated limb. Three patients had liver lesions. Nineteen patients had elevated liver enzymes, 32 patients had elevated erythrocyte sedimentation rate and 12 were anaemic. Two patients tested positive for hepatitis $\mathrm{C}$ virus and three were positive for hepatitis B virus (HBV). One of the 19 patients with fatty liver tested positive for HBV. Two of the patients with fatty liver infiltration had elevated glycatedhaemoglobin levels and confirmed diabetes mellitus type II.

Conclusion Nearly half $(44,8 \%)$ had remaining metal fragments from explosives of unknown composition harboured in various parts of their bodies. All patients identified with lesions and nodules are being followed up locally. As of now, we cannot anticipate the long-term health consequences of living with metal residuals from modern explosive weapons embedded in body organs and tissue.

\section{Strengths and limitations of this study}

- Strengths of this study include a representative sample of the patients attending rehabilitation in Gaza, a response rate of $99 \%$, the close cooperation with the local staff and the conduction of the study in Arabic.

- It is a limitation that 10 per cent of our data were missed due to the unavailability of diagnostic equipment or services in the hospital.

- We conducted our follow-up study in Gaza, occupied Palestinian territories, where there is no death register, limited cancer registration and where autopsies seldom are performed for cultural reasons. The lack of systematic health registers and digital patient records pose methodological limitations in our study.

- We cannot exclude that patients with traumatic amputations and/or other trauma exposing them to heavy metal contaminations from weapons might have succumbed prior to the start of our research on amputees in 2014.

- We do not know the metal composition of the weapon residuals detected in our patients. We can thus not conclude if such weapon shrapnel(s) may pose health risks to war-trauma patients.

\section{BACKGROUND}

The Palestinian population in Gaza has lived through four large military incursions during the last decade. An increasing part of the Gazan civilian society is living with disability from a wide variety of war related trauma. In 2017, nearly 128000 Palestinians were living with disabilities in Gaza according to the Palestinian Central Bureau of Statistics, constituting nearly $6.4 \%$ of Gaza's population of 2 million people. ${ }^{1}$ Amputation injuries from explosive attack weapons are increasing in Gaza. ${ }^{2}$

The Palestinian as well as international medical communities have long warned of potential harmful health effects of novel weapons used on Gaza. It has been feared that some of the weapons could cause severe 
bodily harm beyond the acute trauma. ${ }^{3-8}$ Modern high energy blast-weapons cause injuries which often leave survivors with fragments from explosive weapons metal casings (shrapnels) embedded in body tissues or solid body organs. Retained weapon residuals may affect a person's health ranging from local or systemic toxicities, to foreign body reactions or malignancies. ${ }^{6}$

In 2009 it was suggested to conduct mandatory systematic follow-up of survivors with war-related trauma in Gaza. ${ }^{7}$ Tissue samples from extremity amputation stumps of Palestinians following the military attacks in 2006 and 2009 showed high levels of heavy metals, metals well known to be carcinogenic in humans. ${ }^{8}$

We have previously reported the mechanisms and severity of injury, demographics and psychosocial status among 254 Gazan patients with war-related, traumatic extremity amputations. ${ }^{9-11}$ The patients we examined during these studies also presented a variety of medical symptoms and findings we could not ignore.

In this paper we describe the findings from medical examinations done in 94 of the 254 traumatic amputees.

\section{MATERIAL AND METHODS Study participants}

The study population included 254 Palestinian patients with war-related traumatic amputations sustained between 2006 and 2016. The patients were attending various rehabilitation efforts at the Artificial Limbs \& Polio Center (ALPC) in Gaza. ${ }^{12}$ ALPC is Gaza's main rehabilitation centre for amputees. The 254 patients make up the total number of registered patients at the centre with warrelated amputations from military incursions on Gaza from 2006 to 2016.

\section{Mechanisms of injuries}

Each included patient was asked to report on types and modes of weapon or explosive they knew or believed had caused the injury leading to their extremity amputation. The various causative weapons are described in detail in a previous publication. ${ }^{10}$

\section{Clinical examination}

We performed standardised clinical examination of each of the 254 amputated patients with the medical history taken by an experienced physician.

The investigation included measurement of heart rate, arterial blood pressure, body weight and patient's heights. The further clinical examination included palpation of the abdomen, auscultation of lungs and heart, examination of the skin and amputation stump and palpation of all lymph node stations.

\section{Referral for secondary care}

Patients we considered to have symptoms of potential serious illness or patients with abnormal findings from any organ system were then offered subsequent referral for secondary care. Following informed consent and in agreement with local health authorities, we then referred 94 of the patients to Al-Shifa Hospital in Gaza for further diagnostic clinical exploration, radiology and laboratory tests. Eleven patients refused the referral.

\section{Radiological and laboratory examinations}

A team consisting of three senior medical doctors; one radiologist, an orthopaedic surgeon and one internist were made at Al-Shifa Hospital, Gaza's main referral centre. The team was in charge of the medical investigations, imaging, laboratory tests and follow-ups.

Following referral, each patient was examined with CT of the abdomen and the chest, ultrasound (US) investigation of the abdomen and MRI of the amputation stump(s). Clinical chemistry tests included erythrocyte sedimentation rate (ESR), complete blood count, kidney and liver function tests, serum glucose, (, creatinekinase, lactatedehydrogenase and tests for hepatitis B and hepatitis C.

Due to insufficient diagnostic equipment and technical failure of the CT machine, we had to resort to US imaging when it was not possible to use the CT machine for the abdominal examinations. Four of the patients did not receive a CT scanning of the abdomen.

Due to the limited transportation resources available in Gaza and the patient's dire economic situation, we decided to hire a suitable van with driver from a local Non-Governmental Organisation to transfer wheelchair patients and patients with disabilities. A physiotherapist from ALPC familiar with the amputees accompanied every patient to their appointments at the hospital.

\section{Ethics}

The studies were approved in Norway by the Regional Ethical Committee (approval number: 2016/1265/ REK nord); in Gaza by the local health authorities; the board of Al-Shifa Hospital, and the Director of the ALPC. The Palestinian Ministry of Health approved the study through the Helsinki ethics approval committee in Gaza. All included patients gave written informed consent following detailed explanation in Arabic of the study objectives and procedures. No economical compensation was offered to the patients except for covering their transportation expenses from home to hospital. All patients were informed that they could withdraw their consent and leave the study at any time. One participant withdrew.

One hundred and five patients with symptoms and findings indicative of serious illness were offered referral for secondary care, of whom 94 accepted to be referred for the follow-up at Al-Shifa Hospital.

The obstructions and difficulties caused by the strict siege in referring Palestinian patients residing in Gaza for needed medical examinations, follow-up or treatment outside Gaza remains a serious ethical dilemma, also in conducting this study. ${ }^{13-15}$ Similarly, the exhausted research resources and lack of biochemistry and genetical testing in Gaza secondary to the siege, limited our research possibilities. 
Table 1 Characteristics of patients referred to secondary care $(n=94)$

\begin{tabular}{llc}
\hline Variables & $\begin{array}{l}\text { Number of } \\
\text { patients (N) }\end{array}$ & Per cent (\%) \\
\hline Palestinian & 94 & 100 \\
Male & 88 & 94 \\
Amputated in drone attack & 48 & 51 \\
Reduced general condition & 61 & 24 \\
Enlarged lymph nodes & 39 & 16 \\
Symptoms from stump & 20 & 8 \\
Symptoms from abdomen & 24 & 9 \\
Symptoms from respiratory & 10 & 4 \\
system & &
\end{tabular}

Age, referral, median (IQR)

Age (years)

$31.5(12.25)$

The patients may be included in more than one of the above categories, as one patient could present more than one symptom and more than one finding.

${ }^{*}$ Reduced general condition: the patient presented symptoms of possible serious illness such as night sweat, malaise, reduced appetite, problems with natural functions (urinary tract system or bowel system).

\section{Statistics}

Descriptive data analysis was conducted in SPSS Statistics V.22.0 (SPSS Inc, Chicago, Illinois, USA) and Stata 15 (StataCorp. 2015. Stata Statistical Software: Release 15. College Station, Texas: StataCorp LP).

\section{RESULTS}

\section{Demographics, symptoms and findings}

The majority of the referred patients were young (median 31.5 years) males $(88 / 94,92.6 \%)$.

During the initial clinical examinations, we found 105 patients with symptoms and/or signs of potential serious illness. Ninety-four accepted our recommendation to be referred to Al-Shifa Hospital for in-depth medical investigations. The patients presented with a variety of symptoms and findings: 24 had symptoms from the abdomen, 27 patients had problems with their natural functions such as urinary tract and bowel system dysfunction, while 10 had symptoms from the lungs. Sixty-one patients presented with reduced general condition and had symptoms including night sweats, malaise, self-reported longterm fever, weight loss and reduced appetite.

We found ulceration, palpable lumps or pain in the extremity amputation stumps of 20 patients. Palpable and enlarged lymph nodes were detected in 39 of the patients.

\section{Radiology findings}

The ultrasound examinations showed fatty liver infiltration in 19 of 90 patients (20\%). Three patients had lung nodules and 10 patients had atelectasis on chest CT. Three patients had liver lesions on CT abdomen.
Twelve patients had weaponry remains in the form of metal fragments (shrapnels) in the chest; five had shrapnel(s) in the abdominal region and one in the scrotum.

We found metal shrapnel(s) in the extremity amputation stump of 26 patients, while 8 patients had metal shrapnel(s) in the non-amputated limb (figures 1 and 2).

Pathologically enlarged lymph nodes were found in six patients on chest CT, six located axillary and one brachially.

\section{Mechanism of injury}

More than half $(48 / 94)$ of the total referred patients had been amputated in attacks with explosive weapons shot from unmanned aerial vehicles (or drones). Fourteen of the 19 patients with liver changes $(73.7 \%$ ) had been amputated during aerial attacks by drone-delivered explosive weapons.

\section{Inflammation and liver function tests}

Nineteen patients had elevated liver enzymes, 32 patients had elevated ESR and 12 patients were anaemic. Two patients tested positive for hepatitisC virus and three were positive for hepatitisB virus (HBV) (one of 19 patients with fatty liver tested positive for $\mathrm{HBV}$ ). Two patients with fatty liver infiltration had elevated HbAlc levels and confirmed diabetes mellitus type II. One patient was diagnosed with autoimmune hepatitis with positive antismooth muscle antibody.

\section{DISCUSSION}

The 94 patients we referred to Al-Shifa Hospital for further investigations were mostly young males in their early 30 s (median age 31.5 years). Twenty per cent had liver changes with fatty infiltration on ultrasound examination of the abdomen. More than half (48/94) of them had lost limbs following attacks with explosive weapons delivered by drones. Among the patients with liver changes, 14 of $19(73.7 \%)$ had been amputated during aerial attacks with drone-delivered explosive weapons. Metal shrapnel embedded in body tissue were found in almost half of the referred patients. Three patients had liver lesions and three patients had chest nodules on CT. Atelectasis were found in 1 of 10 patients. Blood results revealed elevated ESR in one-third of the patients.

\section{Fatty liver infiltration}

One in five of the patients we referred in this study had morphological changes typical of non-alcoholic fatty liver disease (NAFLD) on abdominal US. Ultrasound is considered to be the best low cost screening method for moderate-to-severe fatty liver. ${ }^{16}$ Religious rules and prohibition of alcohol in Gaza led us to rule out alcohol as a likely cause for the liver changes. NAFLD is an umbrella term for liver disease characterised by hepatic steatosis in patients with low or no alcohol consumption. The changes in the liver may progress to cirrhosis and eventually hepatocellular carcinoma. ${ }^{17}$ 


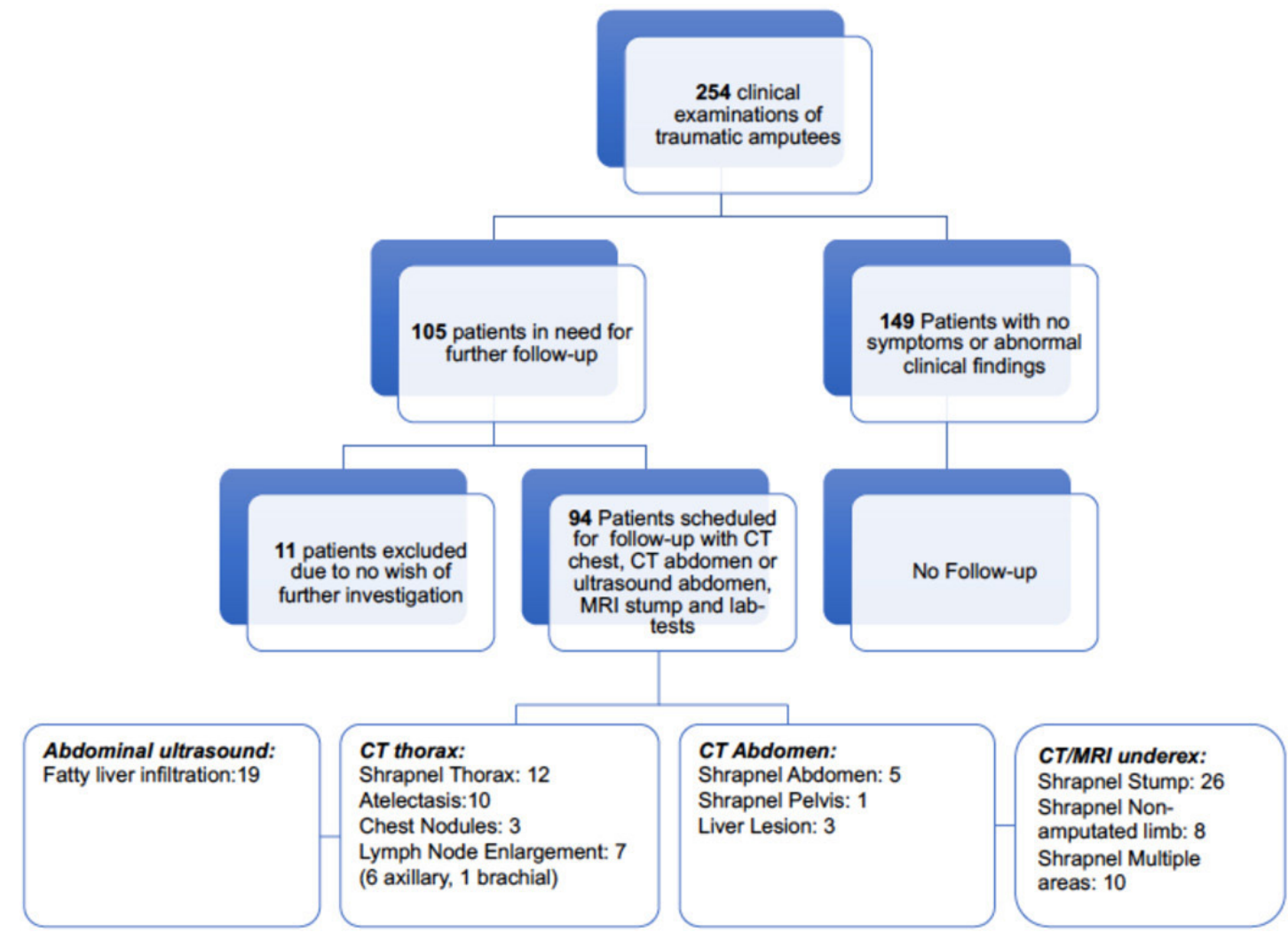

Figure 1 Patient flowchart. Number of patients referred to secondary care and the results of the medical follow-up.

One patient had hepatitis B and two patients were diagnosed with diabetes mellitus type II. Both diseases may cause similar liver changes. ${ }^{17}$ Blood tests revealed a high number of patients with elevated ESR indicating an inflammatory response.

NAFLD is more common in the old patients with metabolic syndrome. Our patients were young and otherwise healthy Palestinians living in Gaza who had suffered serious war injuries with modern explosive weapons. ${ }^{10}$ The patients did have limited physical activity due to their

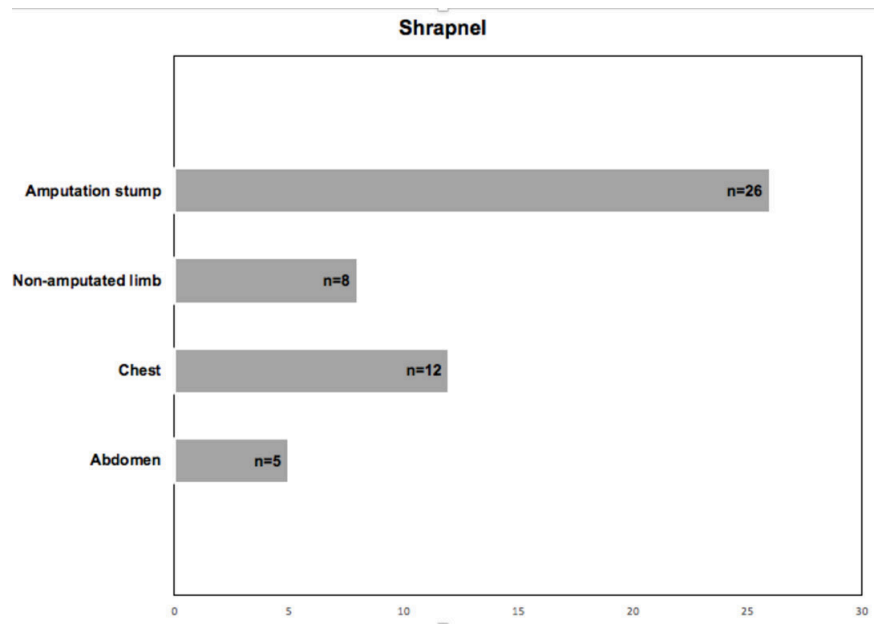

Figure 2 Shrapnel embedded in body tissue. Number of patients and location of metal weapon fragments (shrapnels) in cases of residual weapon shrapnel(s) in body tissue inpatients surviving traumatic amputations. limitation of movement secondary to their amputation handicaps. We cannot rule out a role of reduced activity level, but doubt that this alone explains the development of fatty liver infiltration. Due to the extent of their war injuries, it is reasonable to assume that some of the amputees in our study had long intensive care unit (ICU) stays. Secondary NAFLD is common in ICU patients. ${ }^{18}$

\section{Embedded shrapnel in tissue}

Almost half of the survivors in this study had metal fragments from weapons embedded somewhere in their bodies. Retained embedded weapon metal fragments in war injuries has traditionally been thought of as harmless, and are therefore seldom removed surgically. ${ }^{6}$ However, research on cell-lines, laboratory animals and humans are providing increasing evidence of the opposite. ${ }^{19-22}$ The American Armed Forces Institute of Pathology started in 2013 to collect longitudinal data of veterans with retained shrapnel in body tissue due to the concern of hazardous health effects of embedded shrapnel and the lack of clinical guidelines in the follow-up of the veterans. ${ }^{6}$

The researchers conclude that there is a need of studying the chemical composition of retained metal fragments in addition to close clinical follow-up with laboratory tests due to the risk of adverse health effects. ${ }^{6}$ In Gaza such remaining metal shrapnels are seldom surgically removed. We do not know the composition of the metals in the shrapnels embedded in the amputees in our Gaza cohort. Carcinogenic heavy metal residuals from weapons, such as nickel and cobalt, have been shown in wounds of surviving 
Palestinians with traumatic amputations following the various military attack in Gaza in 2006 and 2009.

The effects of heavy metals as war residuals have been linked to birth defects in children in Gaza and suggested to play a causative role in embryonic development defects when parents are exposed to such contaminants from weapons. ${ }^{23}$ A recent study found significant higher content of heavy metals in hair samples from women in Gaza exposed to military attacks compared with women not exposed to attacks. The heavy metal concentrations in hair from newborns correlated with the load found in their mothers. ${ }^{24}$

We consider it vital to further study the chemical composition of the metal shrapnel(s) embedded in the amputee's body tissue in order to better understand the potential health risk such weapon residuals represent. Hence, we conclude this paper with more unanswered than answered questions.

We cannot offer an all-embracing explanation to the pathological findings in the studied cohort of mainly young traumatic amputees in Gaza. We can neither confirm nor reject possible systemic effects of heavy metal contamination of remains from explosive weapons in the body tissues of these Palestinian patients who have survived serious traumatic amputations during the various military attacks on Gaza.

We do recommend close and mandatory medical follow-up for war-trauma patients in Gaza in general, and in particular in those patients who survive attacks with explosive weapons who have weapon residuals in their body tissues. It should also be considered to remove embedded shrapnel(s) surgically, both for pain relief and to analysis the chemical composition of removed fragments.

\section{Limitations}

Ten per cent of our data were missed due to the unavailability of diagnostic equipment or services in the hospital. These deficiencies are caused by the long-lasting siege of Gaza which severely hampers the supply-chain for healthcare material, analytical supplies for hospital laboratories and hospital equipment. Due to the lack of electronic files, we don't know the previous serological status of each patients or if they received any blood transfusion. This can cause confusion bias and therefore we have included this under the limitations in our paper.

The CT machine broke down twice after we had started our investigations, and in addition we realised that the CT machine was needed for more urgent cases. We therefore decided to perform most of the abdominal examinations by ultrasound. All of the patients received thoracic CT scans. MRI investigations were limited because many patients in the cohort had metal shrapnels. The patients that could not have MRI of the stump received a CT scanning of the stump instead.

We conducted our follow-up study in Gaza, occupied Palestinian territories, where there is no death register, limited cancer registration and where autopsies seldom are performed for cultural reasons. The lack of systematic health registers and digital patient records pose methodological limitations in our study.

We cannot exclude that patients with traumatic amputations and/or other trauma exposing them to heavy metal contaminations from weapons might have succumbed prior to the start of our research on amputees in 2014. We do not know the metal composition of the weapon residuals detected in our patients. We can thus not conclude if such weapon shrapnel(s) may pose health risks to wartrauma patients. The local Palestinian hospitals in Gaza had to cancel planned operations due to the severe lack of resources due to the 12 years of siege and blockade. Fourteen of Gaza's public hospitals were in risk of partial or complete closure due to the fuel and electricity crisis. ${ }^{25}$ As a result of these serious sanctions on Gaza, it took us more than 1 year to have the 93 patients undergo all scheduled examinations.

The further needed follow-up of the amputated patients in this study will be limited by the severe lack of capacity and resources in the Gazan healthcare system resulting from the collective punishment of the long-lasting siege and the restrictions on Gaza's health sector. ${ }^{26}$

\section{INTERPRETATION}

One in five of 94 war-related amputees were unexpectedly found to have fatty liver infiltration on abdominal ultrasound. Nearly half $(44.8 \%)$ had remaining metal fragments from explosives (shrapnels) of unknown composition harboured in various parts of their bodies.

We do not have a certain hypothesis to explain our findings.

All patients identified with lesions and nodules are being followed up locally. As of now, we cannot anticipate the long-term health consequences of living with metal residuals from modern explosive weapons embedded in body organs and tissue. We recommend close medical follow-up for trauma patients in Gaza who survive attacks with explosives and have metal residuals remaining in their body tissues.

Acknowledgements We would like to extend a sincere thanks to the participating patients and their families. The support and invaluable contributions from Dr Ali Watti MD, Technical Coordinator of ALPC, Mrs Neveen Alghussien, Data Entry Officer at ALPC, Foaad Hamed and the rest of the professional staff at ALPC is greatly appreciated.The publication charges for this article have been funded by a grant from the publication fund of UiT The Arctic University of Norway

Contributors HEH-L contributed study design, data collection, data entry, data analysis, interpretation of the results, the primary draft of the manuscript writing, editing the manuscript, literature search and final approval of the manuscript. Al contributed to study design, patient inclusion, data collection, data transfer, revising the manuscript and final approval of the manuscript. YA-B contributed to study design, patient inclusion, data collection, data transfer, revising the manuscript and final approval of the manuscript. IAH contributed to study design, patient inclusion, data collection, data transfer, revising the manuscript and final approval of the manuscript. MM contributed to study design, patient inclusion, data collection, data transfer, revising the manuscript and final approval of the manuscript. SS contributed to study design, patient inclusion, data collection, data transfer, revising the manuscript and final approval of the manuscript. NS contributed to study design, patient inclusion, data collection, data transfer, revising the manuscript and final approval of the manuscript. MG contributed the original research idea, the 
study design, interpretation of the results, revising and editing the manuscript and final approval of the manuscript.

Funding The Norwegian street-artist AFK provided 1500 Euros to this project, which was used to cover patient's transportation costs.

Competing interests None declared.

Patient and public involvement Patients and/or the public were not involved in the design, or conduct, or reporting, or dissemination plans of this research.

Patient consent for publication Not required.

Ethics approval All patients completed written consent prior to participating. The study was approved by the Regional Ethical Committee (approval number: 2016/1265/REK Nord) in Norway and the Committee for Helsinki ethics approvals in Gaza.

Provenance and peer review Not commissioned; externally peer reviewed.

Data availability statement The data sets used during the current study are not publicly available as the authors did not apply to any ethical committees for the permission to share the data. In this particular context, sharing of data could raise safety concerns for the participants in the study and thus considered unethical.

Open access This is an open access article distributed in accordance with the Creative Commons Attribution Non Commercial (CC BY-NC 4.0) license, which permits others to distribute, remix, adapt, build upon this work non-commercially, and license their derivative works on different terms, provided the original work is properly cited, appropriate credit is given, any changes made indicated, and the use is non-commercial. See: http://creativecommons.org/licenses/by-nc/4.0/.

\section{ORCID iD}

Hanne Edoy Heszlein-Lossius http://orcid.org/0000-0003-2371-0868

\section{REFERENCES}

1 WAFA. Sharp rise in number of people with disabilities in Gaza strip in the last 10 years-statistics Wafa, 2018. Available: http://english. wafa.ps/page.aspx?id=05gr9ja106662958710ao5gr9j [Accessed 09 May 2019].

2 Arisheh $\mathrm{M}$, Efrat $\mathrm{M}$, Issa-Liftawi $\mathrm{H}$, et al. Report physicians for human rights: amputees the challenges faced by Gaza-strip amputees in seeking medical treatment, 2016. Available: http://www.phr.org.il/wpcontent/uploads/2016/06/Amputees-report-eng.pdf [Accessed 09 May 2019].

3 Gilbert M, Gaza Si. [Summer rain in Gaza]. Tidsskr Nor Laegeforen 2006;126:2136-9.

4 Brooks J. Warfare of the future, today? the dime bomb: yet another genotoxic weapon.2006 grass roots peace, 3, 2006. Available: http://www.grassrootspeace.org/israel_dime_bombs_121206.pdf [Accessed 05 May 2016].

5 Press Tv. Dense inert metal explosive (dime) bombs being used in Gaza. Available: https://www.youtube.com/watch?v=LyBS6j5WR-c [Accessed 28 Oct 2018].

6 Centeno JA, Rogers DA, van der Voet GB, et al. Embedded fragments from U.S. military personnel--chemical analysis and potential health implications. Int J Environ Res Public Health 2014;11:1261-78.

7 Dyer C. Doctors call for children injured in Gaza conflict to be monitored for long term effects of new weapons. BMJ 2009;339:b4664.

8 Skaik S, Abu-Shaban N, Abu-Shaban N, et al. Metals detected by ICP/MS in wound tissue of war injuries without fragments in Gaza. BMC Int Health Hum Rights 2010;10:17.
9 Heszlein-Lossius HE, Al-Borno Y, Shaqqoura S, et al. Life after conflict-related amputation trauma: a clinical study from the Gaza strip. BMC Int Health Hum Rights 2018;18:34.

10 Heszlein-Lossius H, Al-Borno Y, Shaqqoura S, et al. Traumatic amputations caused by drone attacks in the local population in Gaza: a retrospective cross-sectional study. Lancet Planet Health 2019:3:40-7.

11 Heszlein-Lossius HE, Al-Borno Y, Shaqqoura S, et al. Does pain, psychological distress and deteriorated family economy follow traumatic amputation among war casualties? A retrospective, crosssectional study from Gaza. BMJ Open 2019;9:e029892.

12 Artificial Limbs \& Polio Center. Artificial limb and polio center international Commitee of the red cross, 2019. Available: https:// www.icrc.org/en/doc/assets/files/2011/gaza-orthopedic-centre-icrc2011.pdf

13 World Health Organization report. Gaza patients painful journey to cancer treatment, 2019. Available: http://www.emro.who.int/pse/ palestine-news/gaza-patients-painful-journey-to-cancer-treatment. html

14 Middle East Eye. Middle East Eye Palestinians despair of Israeli restrictions on medical treatment outside Gaza, 2019. Available: https://www.middleeasteye.net/news/palestinian-families-decryisraeli-delays-restrictions-access-medical-treatment-outside-gaza

15 The electronic Intifada. The electronic Intifada: 54 patients dies waiting for Israel to let them out of Gaza, 2019. Available: https:// electronicintifada.net/blogs/ali-abunimah/54-patients-died-waitingisrael-let-them-out-gaza

16 Mehta SR, Thomas EL, Patel N, et al. Proton magnetic resonance spectroscopy and ultrasound for hepatic fat quatification. Hep Reaserach 2010;40:399-406.

17 Chopra S. Management of nonalcoholic fatty liver disease in adults UpToDate, 2019. Available: https://www.uptodate.com/contents/ management-of-nonalcoholic-fatty-liver-disease-in-adults\# H244507317 [Accessed 24 May 2019].

18 Paquot N, Delwaide J. Fatty liver in the intensive care unit. Curr Opin Clin Nutr Metab Care 2005:8:183-7.

19 Gaitens JM, Centeno JA, Squibb KS, et al. Mobilization of metal from retained embedded fragments in a blast-injured Iraq war veteran. Mil Med 2016;181:e625-9.

20 Kalinich JF, Emond CA, Dalton TK, et al. Embedded weaponsgrade tungsten alloy Shrapnel rapidly induces metastatic highgrade rhabdomyosarcomas in F344 rats. Environ Health Perspect 2005;113:729-34.

21 Miller AC, Mog S, McKinney L, et al. Neoplastic transformation of human osteoblast cells to the tumorigenic phenotype by heavy metal-tungsten alloy particles: induction of genotoxic effects. Carcinogenesis 2001;22:115-25.

22 McDiarmid MA, Engelhardt SM, Dorsey CD, et al. Surveillance results of depleted uranium-exposed Gulf War I veterans: sixteen years of follow-up. J Toxicol Environ Health A 2009;72:14-29.

23 Naim A, Al Dalies H, El Balawi M, et al. Birth defects in Gaza: prevalence, types, familiarity and correlation with environmental factors. Int J Environ Res Public Health 2012;9:1732-47.

24 Manduca P, Diab SY, Qouta SR, et al. A cross sectional study of the relationship between the exposure of pregnant women to military attacks in 2014 in Gaza and the load of heavy metal contaminants in the hair of mothers and newborns. BMJ Open 2017;7:e014035.

25 WHO. Gaza's health care sector faces fuel and electricity crisis. Available: http://www.emro.who.int/pse/palestine-infocus/gazashealth-sector-faces-fuel-and-electricity-crisis.html [Accessed 29 Aug 2017].

26 Piper R. United nations report: Gaza ten years later. Available: https://unsco.unmissions.org/sites/default/files/gaza_10_years_ later_-_11_july_2017.pdf [Accessed 8 Feb 2018]. 